\title{
AVALIAÇÃO DE FORMAÇÃO DE BIOFILME PERIFÍTICO E IDENTIFICAÇÃO DE MICROALGAS EM UM SISTEMA PILOTO ALGAL TURF SCRUBBER
}

\author{
ALVES, G.1; RIZZETTI, T. M.2; WILGES, H. G. ${ }^{3}$, SZARBLEWSKI, M.S.4; BENITEZ, L.B. 5; SANCHEZ-BARRIOS, A. ; \\ HOELTZ, M.7; SCHNEIDER, R.C.S 8
}

PALAVRAS-CHAVE: Algal Turf Scrubber, perifíton, microalgas.

\begin{abstract}
RESUMO
Os corpos d'água costumam sofrer eutrofização como resultado do excesso de nutrientes e isso impulsionou a necessidade de desenvolvimento de tecnologias para auxiliar e manter a qualidade da água. Os sistemas Algal Turf Scrubber (ATS) são alternativas para a preservação e o monitoramento das condições da água, bem como proporcionar sustentabilidade ambiental e financeira ao longo do tempo. Com base nisso, objetivamos estudar 0 potencial de desenvolvimento de um biofilme em um sistema piloto de ATS instalado em um lago durante o período de outono/inverno. Para isso, foram monitorados alguns parâmetros da água, avaliado o rendimento de biomassa e identificadas as microalgas no perifíton. As estações selecionadas e as condições ambientais complicaram o desenvolvimento do biofilme. Apesar disso, obteve-se um rendimento de biomassa de 4,67 $\mathrm{g} \mathrm{m}$ 2 d-1 e sua composição de lipídios foram de 10\%, em que os ácidos graxos em maior abundância foram o ácido palmítico e o oleico. A partir de estudos morfológicos e taxonômicos, quatro gêneros de microalgas foram identificados: Chlorella; Desmodesmus; Pedriastrum e Spirogyra. Acredita-se que analisando em outras estações e variações das condições ambientais seria possível chegar a um maior desenvolvimento do perifíton e, consequentemente, a melhores tratamentos para massas de água eutrofizadas.
\end{abstract}

\section{EVALUATION OF PERIPHYTIC BIOFILM FORMATION AND IDENTIFICATION OF MICROALGAE IN AN ALGAL TURF SCRUBBER PILOT SYSTEM}

KEYWORDS: ATS, periphyton, microalgae.

\begin{abstract}
Water bodies often suffer from eutrophication as a consequence of excess nutrients, increasing the need for developing technologies to assist and maintain the quality of the water. Algal Turf Scrubber (ATS) systems are alternatives for the preservation and monitoring of water conditions, as well as providing environmental and financial sustainability through time. Based on this, we aim to study the potential of biofilm development in an ATS pilot system placed on a lake during the Fall/Winter period. For this, we monitored some water parameters, evaluated the yield of biomass, and identified microalgae in the periphyton. The seasons selected and the environmental conditions complicated the development of the biofilm. Despite this, the biomass yield was $4.67 \mathrm{~g}$ $\mathrm{m}-2 \mathrm{~d}-1$, and its lipid composition was $10 \%$, where the fatty acids in greater abundance were palmitic and oleic acid. Morphological and taxonomic studies identified four genera of microalgae: Chlorella, Desmodesmus, Pedriastrum, and Spirogyra. We believe that analyzing other seasons and variations of the environmental

${ }^{1}$ Acadêmica do Curso de Engenharia Ambiental na Universidade de Santa Cruz do Sul. Email: giselealves9@hotmail.com

2 Doutora em Ciências e Pós-doutoranda em Tecnologia Ambiental na Universidade de Santa Cruz do Sul. E-mail: tielem@unisc.br

3 Mestranda em Tecnologia Ambiental na Universidade de Santa Cruz do Sul. E-mail: helena.wilges92@gmail.com

${ }^{4}$ Mestrando em Tecnologia Ambiental na Universidade de Santa Cruz do Sul. E-mail: mateusilva91@hotmail.com

5 Doutora em Microbiologia, e docente do Departamento de Ciências da Vida, Universidade de Santa Cruz do Sul. E-mail: lisianne@unisc.br

${ }^{6}$ Doutora em Fisiologia Vegetal e Pós-doutoranda em Tecnologia Ambiental na Universidade de Santa Cruz do Sul. E-mail:

andmari.sb@gmail.com

7 Doutora em Microbiologia, e docente do Programa de Pós-graduação em Tecnologia Ambiental, Universidade de Santa Cruz do Sul. E-mail: michelehoeltz@gmail.com

8 Doutora em Química, e docente do Departamento de Ciências, Humanidades e Educação, Universidade de Santa Cruz do Sul. E-mail: rosana@unisc.br
\end{abstract}


conditions could lead to a greater development of the periphyton and, as a consequence, better treatments for eutrophicated water bodies.

\section{INTRODUÇÃO}

0 processo de eutrofização em ambientes aquáticos acarreta no crescimento excessivo das plantas aquáticas, tanto planctônicas quanto aderidas. Como consequência disso, há um desequilíbrio do ecossistema aquático e progressiva degeneração da qualidade da água dos corpos lênticos. Um dos principais problemas relacionados à eutrofização é a proliferação de cianobactérias em detrimento de outras espécies aquáticas. Quando submetidas a certas condições ambientais, muitos gêneros de cianobactérias podem vir a produzir toxinas, e essas toxinas podem chegar a ser fatais aos animais e aos seres humanos (GLIBERT, 2017; STROKAL et al., 2020).

Em decorrência da eutrofização muitos reservatórios e lagos estão perdendo sua capacidade de abastecimento de populações. Buscando informações sobre este fenômeno, ações antrópicas vêm sendo desenvolvidas de forma intensificada e as pesquisas realizadas sobre a eutrofização são fundamentais para 0 desenvolvimento de ações de prevenção e melhoria na qualidade dos recursos hídricos. Nesse sentido, um número crescente de trabalhos vem sendo desenvolvido demonstrando a gravidade do problema (MARTINI et al., 2019; Ll et al., 2017).

Segundo Treichel (2013), o problema de eutrofização está relacionado ao surgimento de nutrientes que chegam aos corpos d'água, a partir das atividades agrícolas desenvolvidas na região, e que podem estar dissolvidos ou em sedimentos que são trazidos por enxurradas. Isso vem acontecendo no Lago Dourado em Santa Cruz do Sul onde já foi possível constatar a eutrofização e a floração de algas tóxicas, gerando uma grande preocupação tanto para a população quanto para a Companhia Riograndense de Saneamento (CORSAN).

Visando soluções para este problema, os sistemas de engenharia para o cultivo de algas bentônicas vêm sendo desenvolvidos com maior eficiência, com maior produtividade de biomassa e, consequentemente, uma maior remoção de poluentes de águas de escoamento superficial ou de águas residuais. Dentre os sistemas destacam-se do tipo Algae Turf Scrubber (ATS) que foi avaliado como uma tecnologia potencialmente rentável para a remoção de nutrientes de efluentes municipais, de aquários, de resíduos líquidos de produtos lácteos e suinocultura (ADEY et al, 2011). Além da remoção de nutrientes de corpos d'água contaminados, esta tecnologia à base de algas apresenta vários benefícios ambientais, visto que durante a captura dos nutrientes as algas produzem biomassa que pode ser usada como subproduto no desenvolvimento de novas tecnologias (YAN et al., 2018).

Nesse contexto, a presente pesquisa tem como objetivo avaliar a formação do perífiton, bem como o rendimento de biomassa, e identificar as espécies de microalgas presentes na comunidade perifítica de um sistema ATS piloto instalado as margens do Lago Dourado, RS, Brasil.

\section{FUNDAMENTAÇÃO TEÓRICA}

\subsection{Eutrofização}


Atualmente, o processo de eutrofização é reconhecido como um dos principais problemas de qualidade da água. Este processo pode trazer alguns males ao recurso hídrico, entre eles destacam-se a proliferação acelerada de macrófitas aquáticas e algas, que podem produzir substâncias tóxicas nocivas à saúde. A eutrofização consiste no enriquecimento do meio provocado, principalmente, quando há boas condições de luminosidade e excesso de nutrientes, por exemplo, nitrogênio e fósforo em águas superficiais (BARRETO et al, 2013). Isto acarreta em uma redução do oxigênio dissolvido provocando um crescimento excessivo de plantas aquáticas, mortandade de peixes e outras espécies aquáticas. Além disso, a eutrofização pode levar à alteração no sabor, no odor, na turbidez e na cor da água, comprometendo o uso tanto para o abastecimento quanto para o lazer (BARRETO et al, 2013).

0 termo eutrofização pode ser um processo natural de aumento de produção de materiais orgânicos que se dá durante a evolução de um ecossistema aquático até que este fique saturado ou por processo antropogênico, com uma alta produção de material orgânico derivado de insumos como fósforo e nitrogênio com uma curta escala de tempo (horas, dias, meses e anos) (LE MOAL et al., 2019). Estas definições, embora sejam semelhantes, envolvem processos que não ocorrem na mesma escala de tempo e, portanto, possuem efeitos ecológicos e sociais diferentes (LE MOAL et al., 2019).

0 monitoramento da qualidade da água nos corpos hídricos é de suma importância para o conhecimento das condições da água em bacias hidrográficas. 0 monitoramento contínuo de corpos d água e a detecção de mudanças significativas nos valores de um ou mais parâmetros servem como indicação da presença de contaminantes na água. Assim, diferentes tecnologias vêm sendo aprimoradas para tornar a avaliação de qualidade de água rápida, eficiente e de baixo custo, por exemplo, o uso de sondas multiparâmetros. Essas sondas são equipamentos capazes de detectar, de forma rápida, a concentração de alguns parâmetros físico-químicos, tal como o pH (potencial hidrogeniônico), OD (oxigênio dissolvido), temperatura, condutividade elétrica, turbidez, compostos nitrogenados, matéria orgânica e clorofila (GARBOSSA et al., 2012).

\subsection{Sistema Algae Turf Scrubber (ATS)}

Em função da eutrofização, há necessidade urgente de tecnologias ecológicas seguras e eficientes de tratamento de água para restaurar esses ecossistemas aquáticos. Nesse sentido, a tecnologia de tratamento de água à base de algas tem recebido atenção por sua alta eficiência e vantagens econômicas. Esta tecnologia denominada ATS utiliza fotossíntese e crescimento algal para remover nutrientes e melhorar a qualidade da água (YAN et al., 2018).

O ATS é um sistema de fluxo de água ecologicamente projetado, que utiliza fundamentalmente a fotossíntese das algas para controlar uma ampla variedade de parâmetros de qualidade de água. Esse sistema foi desenvolvido na década de 1980 no Smithsonian Institution em Washington D.C., nos Estados Unidos, como um biomimetismo da produtividade primária de recifes de corais. As unidades ATS funcionavam para controlar nutrientes, níveis de oxigênio, carbonato de sistemas, incluindo calcificação (através do controle de $\mathrm{CO}_{2}$ ) e para minimizar os compostos tóxicos gerados pela ação antrópica. 0 escalonamento de sistemas ATS se iniciou em meados de 1990 e início do século XXI. O emprego de sistemas ATS variou desde o uso para aquicultura e tratamento terciário de águas residuais até para a remoção de nutrientes de canais agrícolas (ADEY et al., 2013). 
0 sistema ATS consiste em uma comunidade de algas que se desenvolve anexadas a uma tela em uma calha rasa ou pistas, na qual a água é bombeada e essa comunidade assume a forma de um tapete. A água é bombeada de um corpo de água para a pista e as algas removem os nutrientes através da absorção biológica e liberam oxigênio dissolvido, através da fotossíntese, à medida que a água flui pela pista. No final da pista, a água é liberada de volta ao corpo d'água, com uma menor concentração de nutrientes e uma maior concentração de oxigênio dissolvido do que quando foi bombeada para a pista. Os nutrientes que foram removidos ou "limpos" do corpo de água são armazenados na biomassa das algas que crescem na tela. As algas devem ser colhidas aproximadamente uma vez por semana durante a estação de crescimento, removendo assim os nutrientes da hidrovia na biomassa de algas. Além disso, a colheita da biomassa é de suma importância, pois rejuvenesce a comunidade de algas e ajuda a manter altas taxas de crescimento (ADEY et al., 2011; MARTINI et al., 2019).

\subsection{Microalgas}

As microalgas são microrganismos heterogêneos, que podem se desenvolver rapidamente e que necessitam de condições simples de crescimento, como luz, $\mathrm{CO}_{2}$, açúcares, nitrogênio, fósforo e potássio. São seres microscópicos, unicelulares, coloniais ou filamentosos, coloridos e fotoautotróficos. Filogeneticamente, esses microrganismos podem ser procarióticos ou eucarióticos e podem produzir altas taxas de lipídios, proteínas e carboidratos (MATA et al. 2010; DEMIRBAS, 2011; ZHANG et al. 2016).

As microalgas são capazes de converter dióxido de carbono em produtos úteis para o consumo humano (medicinais, alimentícios, produtos de beleza, outros). 0 fitoplâncton e as algas filamentosas são os tipos de população nos quais são encontradas as microalgas, e estas podem estar integradas por diatomáceas, algas verdes e algas douradas (DEMIRBAS, 2011; DEMIRBAS \& DEMIRBAS, 2011; HEMAISWARYA et al., 2011; MITRA et al., 2012; PHUKAN et al., 2011).

Pesquisas tecnológicas com as microalgas têm sido realizadas devido a sua importância nutricional, econômica e ecológica. Muitas microalgas são utilizadas para a produção de alimentos, uma vez que possuem diversas substâncias, como vitaminas, sais minerais, pigmentos, lipídios e ácidos graxos. Além disso, o uso de algas para o tratamento de águas contaminadas traz grandes benefícios ambientais, uma vez que sua biomassa pode ser transformada em produtos de alto valor agregado. Por exemplo, os lipídios são os metabólicos primários produzidos pelas microalgas e que normalmente são usados para a produção de biodiesel, já a composição dos ácidos graxos juntamente com o teor de carotenoides, possuem uma atenção maior, pois podem ser voltados para a produção de produtos de maior valor agregado. A composição bioquímica da biomassa das microalgas é determinada pela natureza de cada espécie algal, pela forma de cultivo e de fatores como a intensidade de luz, temperatura, pH, nutrientes e concentração de $\mathrm{CO}_{2}$ (FERREIRA et al., 2013; MARELLA et al., 2019).

\section{MATERIAIS E MÉTODOS}

\subsection{Unidade ATS piloto}

O sistema ATS foi construído junto ao Lago Dourado, reservatório artificial de água da cidade de Santa Cruz do Sul - RS, localizado próximo ao Rio Pardinho, entre a RS-409 e a BR-471. Ocupa uma área de acúmulo de 
água de 119 hectares e serve para acumulação de 3 milhões de metros cúbicos de água. Segundo a última batimetria realizada tem uma profundidade média de aproximadamente $3 \mathrm{~m}$ (WENZEL, 2012). A confecção e operação do sistema ATS empregado está descrito por Martini et al. (2019). Resumidamente, o sistema ATS foi confeccionado em acrílico de $3 \mathrm{~mm}$ de espessura, apoiado por uma estrutura de ferro com $5 \mathrm{~m}$ de comprimento por $1 \mathrm{~m}$ de largura; uma bomba d'água submersa foi utilizada para controle da vazão e sobre a rampa foram dispostas telas de nylon para a fixação do perífiton (biofilme). Após 28 dias de cultivo foi realizada a coleta do perifiton de maneira manual com o auxílio de raspadores (espátulas e facas). A biomassa foi armazenada em recipientes de $10 \mathrm{~L}$ para o transporte até o laboratório onde uma pequena parte foi separada para o cultivo em reator de bancada e o restante foi submetido a secagem em estufa com circulação de ar forçado (Tecnal TE394/5) com temperatura de $50^{\circ} \mathrm{C}$ (MARTINI et al. 2019).

\subsection{Análises da água no Lago e biomassa}

A análise de água no Lago Dourado consistiu na medição diária dos parâmetros de pH, condutividade e sólidos totais dissolvidos (STD) utilizando uma sonda multiparâmetro (H198194, Hanna Instruments). Além disso, a determinação de nitrogênio e de fósforo foi realizada conforme os métodos descritos pela AMERICAN PUBLIC HEALTH (2015).

As análises da biomassa, a partir da biomassa seca, consistiram na avaliação do rendimento de biomassa e na determinação de lipídios e ácidos graxos. 0 procedimento de preparo de amostra e análise cromatográfica foram as mesmas descritas por Martini et al. (2019).

\subsection{Identificação de microalgas no perifíton}

No laboratório, antes da secagem da biomassa, uma pequena alíquota do perifíton, formado no sistema ATS, foi mantido em um fotobiorreator de bancada e suplementado com uma solução fertilizante contendo NPK (nitrogênio, fósforo e potássio), luz artificial e aeração constante. Após 5 dias de cultivo, foram realizados os estudos morfológicos e taxonômicos. Para as análises de identificação foi empregado um microscópio óptico Motic BA410 com câmera fotográfica e ocular micro metrada acopladas. A sistematização dos táxons foi realizada com base na metodologia descrita em artigos científicos (KAY E BARTON 1991; ADEY ,1993; CHISTI, 2007; GODINHO, 2009; MATA et al., 2010; PHUKAN et al. 2011; RAIL, 2012; ADEY et al., 2013; PACHECO et al., 2015; CARRIJO, 2017).

\section{RESULTADOS E DISCUSSÃO}

\subsection{Avaliação da formação de biofilme perifítico e dos parâmetros da água}

Sabe-se que o perifíton é uma comunidade microbiota constituída por vários micro-organismos, tais como, algas microscópicas, bactérias e fungos que se associam em um substrato. As algas são os componentes majoritários dessa comunidade perifítica e tanto fatores abióticos (luz, temperatura, concentração de nutrientes, pH, salinidade, entre outros) quanto bióticos (por exemplo, fungos, bactérias, vírus, outros) podem afetar o crescimento das microalgas (MATA et. al, 2010). Para avaliar o crescimento de microalgas pode-se utilizar a curva de crescimento, em que é verificado o aumento da densidade celular. Assim, a relação de taxa de crescimento pode ser expressa em número de células (ou biomassa) por tempo e disponibilidade de nutriente (LOPES et al., 
2015). Os estudos realizados em laboratório permitem avaliar este crescimento e identificar quais as condições mais favoráveis à proliferação de microalga, uma vez que é possível controlar a luminosidade, nutrientes e o controle mecânico do sistema. Contudo, em sistemas instalados no meio ambiente, como é o caso do ATS, não é possível avaliar dessa forma, pois existem diversos micro-organismos que contribuem para a formação do perifíton e não há controle dos parâmetros climáticos. Nesse caso, pode-se avaliar o crescimento através do rendimento de biomassa obtida, o qual foi empregado em nossa pesquisa.

Em nosso estudo, o rendimento de biomassa seca obtida empregando o sistema ATS foi de 4,67 $\mathrm{g} \mathrm{m}^{-2} \mathrm{~d}^{-}$ 1. 0 período em que avaliamos o sistema ATS foi entre as estações do outono e inverno e a radiação solar, bem como a temperatura, nessas estações não foi favorável para a produção do biofilme perifítico, quando comparados ao verão em que a luminosidade e temperatura favoreceriam uma maior produção perifíton. Segundo estudos realizados por Gris et al., (2014), a luz é um dos principais parâmetros a ser considerado quando se trata de crescimento e produtividade das microalgas, uma vez que a luz fornece toda a energia necessária para suportar seu metabolismo. No entanto, quando a luz é fornecida em excesso pode causar um dano nas células levando a um stress oxidativo e como consequência acarreta em uma redução na eficiência fotossintética. Além disso, entre os fatores ambientais para o desenvolvimento das microalgas, destaca-se também a temperatura. 0 estudo conduzido por Zhao e Su (2014) descreve que a temperatura ideal para o crescimento de microalgas pode variar entre 15 e $26^{\circ} \mathrm{C}$. Em temperaturas baixas, a atividade enzimática é prejudicada levando à redução da taxa fotossintética.

Conforme Choi e Lee (2015), além de luz para que o processo de fotossíntese ocorra, as algas também precisam de quantidades particulares de nutrientes, o que inclui macro elementos como C, N, P, S, K, Fe (e Si, para o caso das diatomáceas), oligoelementos como Co, Mo e Mn, e vitaminas, como a cianocobalamina e tiamina, a fim de produzirem biomassa e multiplicarem-se. Dessa forma, para monitorarmos as condições de nutrientes da água optou-se pela medição de nitrogênio e fósforo.

A avaliação dos parâmetros de $\mathrm{pH}, \mathrm{P}$ total, $\mathrm{N}$ amoniacal total, condutividade e STD da água do lago Dourado podem ser vistas na Tabela 1, que apresenta a média dos valores medidos nos meses de março a julho de 2019. Os valores de pH, P total, N amoniacal total e STD estão de acordo com a Resolução CONAMA 357 para águas doces (BRASIL, 2005), uma vez que os valores médios obtidos neste estudo estão na faixa aceitável disposta na resolução mencionada. Quanto à condutividade não existe um padrão na legislação (Piratoba, et al. 2017) contudo, de acordo com Von Sperling (2007, apud Piratoba, et al. 2017), "as águas naturais apresentam teores de condutividade na faixa de 10 a $100 \mu \mathrm{S} \mathrm{cm}-1$, e em ambientes poluídos por esgotos domésticos ou industriais os valores podem chegar até $1000 \mu \mathrm{S} \mathrm{cm}^{-1}$ ". Assim, conclui-se que a média do valor de condutividade está dentro da faixa de águas naturais.

Tabela 1. Parâmetros físico-químicos das amostras da água do Lago Dourado no período de avaliação da formação do perífiton.

\begin{tabular}{ccc}
\hline Parâmetro & Média & Desvio padrão \\
\hline $\mathrm{P}\left(\mathrm{mg} \mathrm{L}^{-1}\right)$ & 0,04 & 0,02 \\
$\mathrm{~N}\left(\mathrm{mg} \mathrm{L}^{-1}\right)$ & 0,76 & 0,67 \\
$\mathrm{pH}$ & 7,39 & 0,66
\end{tabular}




\begin{tabular}{ccc} 
Condutividade $\left(\mu \mathrm{sm}^{-1}\right)$ & 72,1 & 17,20 \\
$\mathrm{STD}\left(\mathrm{mg} \mathrm{L}^{-1}\right)$ & 32,8 & 5,10 \\
\hline
\end{tabular}

Com base nisso, entende-se que as condições de formação do perifíton no período avaliado não foram as mais adequadas afetando de maneira negativa o crescimento do perifiton. Embora as condições climáticas de baixas temperaturas, luminosidade e concentração de $\mathrm{N}$ e $\mathrm{P}$ tenham sido desfavoráveis, ocorreu a formação de perifíton e foi possivel encontrar o rendimento da biomassa perifítica. Consequentemente, o sistema ATS, por manter a formação de biofilme, apresenta potencialidade para remover os nutrientes da água.

0 monitoramento da água e a avaliação do rendimento da biomassa permitiram concluir que o ATS mesmo em condições não propícias mantém o biofilme no sistema; e supõe-se que em maiores concentrações de nutrientes, bem como em estações mais quente, como o período do verão, ocorrerá o aumento da produtividade de perifíton.

\subsection{Identificação de microalgas no Perifíton}

Para a identificação de microalgas no perifíton uma alíquota do perífiton foi cultivada em laboratório e, com isso, procedeu-se a identificação das microalgas cultivada em laboratório com auxílio de microscópio com ampliação de 100x. Como pode ser visto na Figura 1, os gêneros de microalgas identificadas no perifíton do sistema ATS foram a Chlorella, Desmodesmos, Pediatrum e Spirogyra.

Figura 1 - Identificação dos gêneros das microalgas do perifíton cultivadas em escala laboratorial com ampliação 100x em microscópio Motic BA410 A) Chlorella B) Desmodesmus C) Pediastrum D) Spirogyra.
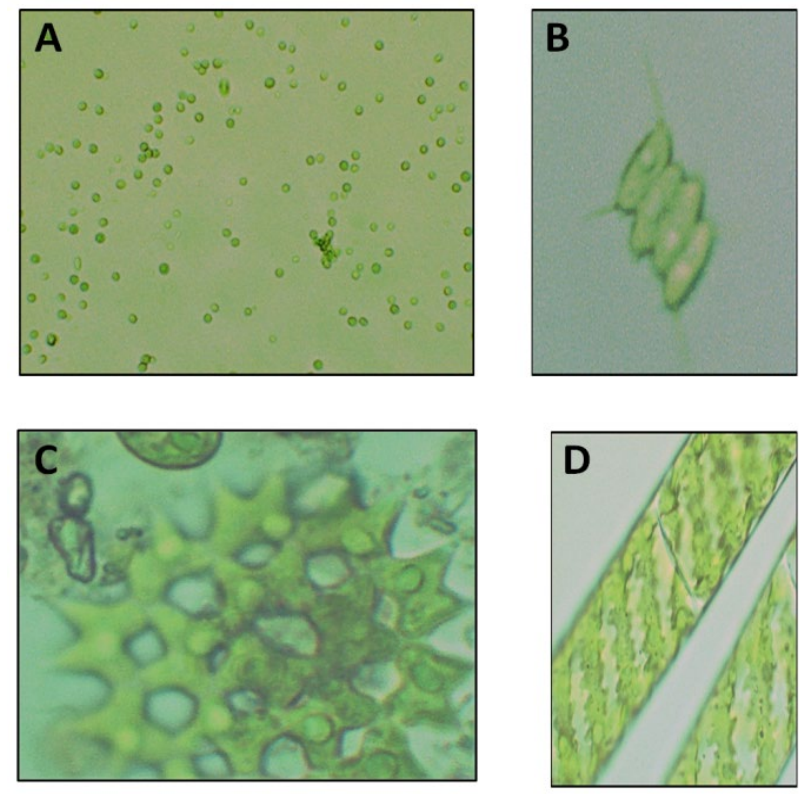

Na Figura 1A observa-se a Chlorella, essa microalga é uma alga verde em que suas células são isoladas com 2,0-10,0 $\mu \mathrm{m}$ de diâmetro com forma esférica, globular ou elipsoidal. Esse gênero pode se desenvolver em águas doces e marinhas, e por isso, alguns estudos relatam essa microalga como universal, uma vez que pode se desenvolver em diferentes habitats, chegando a ser encontrada nas águas de lagoas e das valas, no solo úmido, 
na superfície dos troncos de árvore (KAY E BARTON 1991, PHUKAN et al. 2011). Sua principal forma de reserva é o amido, mas sob certas condições de cultivo, são grandes produtoras de óleo (SANTOS et al., 2011).

Também foi possível identificar o Gênero Desmodesmus (Figura 1B). 0 gênero Desmodesmus é constituído por indivíduos coloniais de vida livre, possui como característica os cenóbios planos que são formados por 2-4-8 ou 16 células dispostas linear ou alternadamente, com seus eixos mais longos paralelos entre si, formando uma linha de células dispostas em uma série ou em duas (GODINHO, 2009).

Como pode ser visto na Figura $1 \mathrm{C}$ foi identificada uma microalga do Gênero Pediastrum. 0 Gênero Pediastrum tem como característica colônias de flutuação livre que possui uma forma de disco estrelada ou plana que pode conter 4-8-16-32-64 ou mais células poligonais. Este gênero possui células cenocíticas, paredes lisas ou ásperas, células marginais com ou sem processo e geralmente diferente em formato de células interiores (RAIL, 2012).

Na Figura 1D são observadas células filamentosas em formato cilíndrico sem ramificações e com cloroplastos enrolados em espirais, característica principal do gênero Spirogyra, que possui longas células filamentosas cilíndricas e sem ramificação. Sua reprodução é sexuada e pode ser tanto escalariforme quanto lateral. Os filamentos de Spirogyra são usualmente livre-flutuantes e, raramente, podem estar fixos em um substrato. Os filamentos são uniseriados, simples e constituídos por células cilíndricas, em geral até 30 vezes mais longas que largas raro ao redor de duas vezes mais largas que longas (CARRIJO, 2017).

Os gêneros Desmodesmus, Chlorella e Pediastrum identificados na pesquisa pertencem à classe de algas verdes, do Filo Chlorophytae e classe Chlorophyceae, essas algas possuem como característica um grande potencial para a produção de biomassa, com destaque para o Gênero Chlorella, grande produtora de biomassa e lipídios sob determinadas condições de cultivo (CHISTI, 2007; MATA et al., 2010). Estudos realizados por Adey (2013), utilizando duas unidades ATS implantadas no rio Grande Wicomico (GWR) por 22 meses para analisar o papel do substrato no aumento da produtividade de algas e na remoção de nutrientes, encontrou táxons de algas Ochrophyta, que são as diatomáceas (54\%), Chlorophyta que são as algas verdes (24\%), filo ao qual pertence as algas encontradas neste estudo e Cianobactérias, que são as algas azul-esverdeadas (22\%). Esse método aumentou a remoção de nutrientes (Nitrogênio e Fósforo) pela biomassa de algas em 3,5 vezes, assim como a produtividade de biomassa.

Já o Gênero Spyrogira, também identificada, pertence à classe das algas verdes filamentosas, Filo Phragmoplastophyta, e pode ser mais comum em águas doces e apresentar em sua composição $21 \%$ de lipídios, dependendo das condições de cultivo. 0 gênero Spyrogira, assim como o filo Chlophyta, a qual pertence os gêneros encontrados, possuem pigmentos como clorofila a e b, os quais são responsáveis pela sua cor verde. Já em determinadas condições de cultivo, a Spirogyra desenvolve pigmentos secundários, os carotenoides que apresentam uma coloração amarela ou laranja. Este gênero possui uma alta produtividade de biomassa e alta capacidade de acumular açúcar, o que faz com que seja potencialmente usada como substrato para a produção de bioetanol (PACHECO et al., 2015) Experimentos realizados por Adey (1993) em sistema ATS em um canal secundário na região New Hope South da Área Agrícola Everglades da Flórida, de outubro de 1991 a maio de 1992, desenvolveu um perifíton com espécies dos gêneros Cladophora, Spirogyra, Enteromorpha, Stigeoclonium, e uma variedade de diatomáceas filamentosas, obtendo uma remoção de fósforo de $16,3 \%$ total por $15 \mathrm{~m}$ de pista, em 150 dias de cultivo. 


\subsection{Determinação de lipídios e ácidos graxos a partir da biomassa}

A partir da biomassa seca foi possível determinar o teor de lipídios (\%), em que a biomassa apresentou uma concentração de 10,41 \pm 0,35\%. Os gêneros de microalgas encontrados justificam a presença de lipídios, contudo os fatores climáticos e de nutrientes da água podem não ter favorecido a produção de lipídios. Segundo Rawat et al., (2013), a mudança nos padrões de lipídios e síntese dos compostos produzidos pelas microalgas podem estar associados à adaptação das mesmas pelas mudanças climáticas. Com isso, é possível induzir ou aumentar o teor de lipídios pela falta de nitrogênio ou outros fatores de stress.

Mulbry et al., (2010) também avaliaram a biomassa de sistemas ATS de pequena escala em três afluentes da costa Oeste da Baía de Chesapeake em Maryland, no rio Bush, no rio Patapsco e no rio Patuxent, operando de abril de 2007 a abril de 2008. 0 teor de lipídios (\%) no material colhido foi consideravelmente baixo, $0,34 \pm 0,14,0,51 \pm 0,19$ e $0,65 \pm 0,21 \%$ do peso seco respectivamente para cada rio. Os resultados são inferiores aos resultados apresentados no presente trabalho, levando em conta que nos dois estudos foram utilizadas águas naturais, com unidades operando de forma contínua em um ambiente exposto às intempéries. Segundo Li et al. (2008) e Converti et al. (2009), concentração de nitrogênio pode ter influência no teor de lipídios, modificando também a produtividade de biomassa, para que haja uma maior produção de biomassa e, consequentemente, maior produção de lipídeos, o nitrogênio disponível deve ser limitado.

Após a determinação do teor de lipídios, procedeu-se a identificação e porcentagem de ácidos graxos presentes na biomassa seca. Como pode ser visto na Tabela 2, o componente majoritário dos ácidos graxos foi o ácido palmítico (C16:0) com 52,7\%, seguido dos ácidos esteárico (C18:0) e oleico (C18:1). Gupta et al., (2016) reportam que os ácidos graxos, como por exemplo, o ácido palmítico e o ácido oleico melhoram a qualidade e o desempenho do biodiesel; e que o teor elevado ácido oleico é essencial para garantir a alta qualidade do biodiesel.

Tabela 2 - Ácidos graxos obtidos na amostra

\begin{tabular}{cccccccccc}
\hline $\begin{array}{c}\text { Ácidos graxos } \\
\text { Porcentagem } \\
(\%)\end{array}$ & C12:0 & C13:0 & C14:0 & C15:0 & C16:0 & C18:0 & C18:1 & C18:2 & C18:3 \\
\cline { 2 - 8 } & 1,8 & 0,2 & 14,2 & 1,6 & 52,7 & 11,0 & 10,8 & 3,13 & 5,6 \\
\hline
\end{tabular}

0 perfil de ácidos graxos podem influenciar algumas propriedades importantes do biodiesel como viscosidade, estabilidade oxidativa e emissão de NO após a sua queima. Com isso, cadeias de ácidos graxos C:16 e C:18 e com baixo grau de insaturação são desejáveis para um biodiesel de boa qualidade (DURRET et al., 2008; HU et al., 2008).

\section{CONSIDERAÇÕES FINAIS}

O perifíton obtido por um sistema em escala piloto da tecnologia Algae Turf Scrubber, avaliado em termos de formação de biofilme e rendimento de biomassa seca, indicou que no período experimental o qual compreendeu parte das estações de outono e inverno dificultou o crescimento do perifíton, uma vez que a luminosidade e temperatura dessas estações não são as mais adequadas. Contudo, observou-se a formação do 
biofilme perifítico e seu rendimento foi de $4,67 \mathrm{~g} \mathrm{~m}^{-2} \mathrm{~d}^{-1}$. Com isso, é possível inferir que em condições mais apropriadas para formação de perifíton a produtividade será maior e, consequentemente, apresenta potencialidade para o controle da eutrofização quando aplicado diretamente nas águas de um lago. 0 monitoramento de alguns parâmetros físico-químicos indicou que a água do lago dourado no período avaliado encontra-se de acordo com o CONAMA. Quatro gêneros de microalgas foram identificados no perifíton: Chlorella, Desmodesmus, Pediastrum pertencentes ao Filo Clorophyta e classe Chlorophyceae; e por fim o gênero Spirogyra, da divisão Charophyta, família Zygnemaceae. Estes gêneros são normalmente encontrados em lagos de água doce. A composição da biomassa apresentou $10 \%$ de lipídios e os ácidos graxos em maior abundância o ácido palmítico e oleico. Assim, os resultados dessa pesquisa indicam que em condições com melhor luminosidade e temperatura, bem como maiores quantidades de nutrientes, pode se obter um maior crescimento de microalgas no biofilme perifítico favorecendo a potencialidade de remoção de contaminantes e a biomassa resultante serem empregada para a formação de bioprodutos.

\section{AGRADECIMENTOS}

A Fapergs pelo auxílio financeiro (protocolo 42082.540.17106.19072019) e ao CNPq (protocolo 310228/20190) e Ministério de Ciência, Tecnologia e Inovações (protocol 01.0144.00/2010).

\section{REFERÊNCIAS}

ADEY, W. H. et al. Algal turf scrubber (ATS) floways on the Great Wicomico River, Chesapeake Bay: productivity, algal community structure, substrate and chemistry1. Journal of phycology, v. 49, n. 3, p. 489-501, 2013

ADEY, W. H., LOVELAND, K. Dynamic aquaria: building living ecosystems. Academic Press, 2011. ISBN 0080469108

ADEY, W.H. et al. Algal turf scrubbing: cleaning surface waters with solar energy while producing a biofuel. Bioscience, v. 61, p. 434-441, 2011.

ADEY, W.; LUCKETT, C.; JENSEN, K. Phosphorus removal from natural waters using controlled algal production. Restoration Ecology, v. 1, n. 1, p. 29-39, 1993.

AMERICAN PUBLIC HEALTH ASSOCIATION, Water Environment, Standard methods for the examination of water and wastewater. 2015.

BARRETO, L. V. et al. Eutrophication Brazilian Rivers. Biosphere Encyclopedia, Scientific Center Knowing - Goiânia, v. 9, n. 16, p. 2167, 2013.

BRASIL. Conselho Nacional do Meio ambiente (CONAMA). Resolução $n^{\circ}$ 357/05. Diário Oficial da República Federativa do Brasil, 2005.

CARRIJO, R. S. et al. Determinação da concentração ótima de meio de cultura para a microalga Spirogyra sp. e de possíveis crioprotetores para sua conservação. Revista Eletrônica de Energia, v. 6, n. 1, 2017.

CHISTI, Y. Biodiesel from microalgae. Biotechnology Advances, v. 25, n. 3, p. 294-306, 2007.

CHOI, H. J., LEE, S. M. Effect of the N/P ratio on biomass productivity and nutrient removal from municipal wastewater. Bioprocess and biosystems engineering, v. 38, n. 4, p. 761-766, 2015.

CONVERTI, A. et al. Effect of temperature and nitrogen concentration on the growth and lipid content of Nannochloropsis oculata and Chlorella vulgaris for biodiesel production. Chemical Engineering and Processing: Process Intensification, v. 48, n. 6, p. 1146-1151, 2009. 
DEMIRBAS, A.; DEMIRBAS, M. F. Importance of algae oil as a source of biodiesel. Energy Conversion and Management, v. 52, n. 1, p. 163-170, 2011.

DEMIRBAS, M. F. Biofuels from algae for sustainable development. Applied Energy, v. 88, n. 10, p. 3473-3480, 2011.

DURRET, T.P, BENNING, C., OHLROGGE, J. Plant triacylglycerols as feedstocks for the productions of biofuels. The Plant Journal, v.54. p. 593-607, 2008.

FERREIRA, S. P., SOUZA-SOARES, L. de, COSTA, J. A. V. Review: microalgae: an alternative source to obtain essential fatty acids. Revista de Ciências Agrárias (Portugal) Vol.36 No.3 pp.275-287, 2013.

GLIBERT, P. M. Eutrophication, harmful algae and biodiversity-Challenging paradigms in a world of complex nutrient changes. Marine Pollution Bulletin, v. 124, n. 2, p. 591-606, 2017.

GARBosSA, L., VANZ, A., SOUZA, R.V., RUPP, G.S. Monitoramento da Qualidade da Água Utilizando Sonda Multiparâmetros no Rio Cubatão (Santa Catarina). In: VIII Simpósio Internacional de Qualidade Ambiental, 2012. Anais do VIII Simpósio Internacional de Qualidade Ambiental, 2012

GODINHO, L. R. Família Scenedesmaceae (Chlorococcales, Chlorophyceae) no Estado de São Paulo: levantamento florístico. Tese de Doutorado. Tese 222f., Universidade de São Paulo, São Paulo, 2009.

GRIS, B. et al. Cultivation of Scenedesmus obliquus in photobioreactors: effects of light intensities and light-dark cycles on growth, productivity, and biochemical composition. Applied biochemistry and biotechnology, v. 172, n. 5, p. 2377-2389, 2014

GUPTA, P. L. et al. Enhanced biomass production through optimization of carbon source and utilization of wastewater as a nutrient source. Journal of Environmental Management, v. 184, p. 585-595, 2016.

HEMAISWARYA, S. et al. Microalgae: a sustainable feed source for aquaculture. World Journal of Microbiology and Biotechnology, v. 27, n. 8, p. 1737-1746, 2011.

$\mathrm{HU}, \mathrm{Q}$. et al. Microalgal triacylglycerols as feedstocks for biofuel production: perspectives and advances. The plant journal, v. 54, n. 4, p. 621-639, 2008.

KAY, R. A., BARTON, L. L. Microalgae as food and supplement. Critical reviews in food science \& nutrition, v. 30, n. 6, p. 555-573, 1991.

LE MOAL, M. et al. Eutrophication: A new wine in an old bottle? Science of the total environment, v. 651, p. 1-11, 2019.

LI, S. et al. Extreme drought causes distinct water acidification and eutrophication in the Lower Lakes (Lakes Alexandrina and Albert), Australia. Journal of Hydrology, v. 544, p. 133-146. ISSN 0022-1694, 2017.

LI, Y. et al. Effects of nitrogen sources on cell growth and lipid accumulation of green alga Neochloris oleoabundans. Applied microbiology and biotechnology, v. 81, n. 4, p. 629-636, ISSN 0175-7598, 2008.

LOPES, T. S. et al. Estudo do potencial de geração de biocombustíveis líquidos a partir de microalgas: Utilização de efluentes agroindustriais e domésticos no desenvolvimento da Chlorella sp. Revista Ciência e Tecnologia, v. 18, n. 33, p. 25-36, 2015.

MARELLA, T. K. et al. Biodiesel production through algal cultivation in urban wastewater using algal floway. Bioresource technology, v. 280, p. 222-228, 2019.

MARTINI, F. A. et al. Periphytic biomass composition and exploitation from algae turf scrubber system. SN Applied Sciences, v. 1, n. 7, p. 765, 2019.

MATA, T. M.; MARTINS, A. A.; CAETANO, N. S. Microalgae for biodiesel production and other applications: a review. Renewable and Sustainable Energy Reviews, v. 14, n. 1, p. 217-232, 2010. 
MITRA, D.; LEEUWEN, V.; HANS J.; LAMSAL, B. Heterotrophic/mixotrophic cultivation of oleaginous Chlorella vulgaris on industrial co-products. Algal Research, v. 1, n. 1, p. 40-48, 2012.

MULBRY, W.; KANGAS, P.; KONDRAD, S. Toward scrubbing the bay: Nutrient removal using small algal turf scrubbers on Chesapeake Bay tributaries. Ecological Engineering, v. 36, n. 4, p. 536-541. ISSN 0925-8574, 2010.

PACHECO, R. et al. The production of pigments \& hydrogen through a Spirogyra sp. biorefinery. Energy conversion and management, v. 89, p. 789-797, 2015.

PIRATOBA, A. R. A. et al. Caracterização de parâmetros de qualidade da água na área portuária de Barcarena, PA, Brasil. Ambiente \& Água-An Interdisciplinary Journal of Applied Science, v. 12, n. 3, p. 435-456, 2017.

PHUKAN, M. M. et al. Microalgae Chlorella as a potential bio-energy feedstock. Applied Energy, v. 88, n. 10, p. 3307-3312, 2011.

RAIL, S. K.; MISRA, P. K. Taxonomy and diversity of genus Pediastrum Meyen (Chlorophyceae, Algae) in east Nepal. Our Nature, v. 10, n. 1, p. 167-175, 2012.

RAWAT, I. et al. Biodiesel from microalgae: a critical evaluation from laboratory to large scale production. Applied Energy, v. 103, p. 444-467, 2013.

STROKAL, M. et al. Cost-effective management of coastal eutrophication: A case study for the Yangtze river basin. Resources, Conservation and Recycling, v. 154, p. 104635, 2020.

TREICHEL, M. Esgoto e adubo causam problemas na água. Gazeta do Sul 2013

WENZEL, J. A. Lago Dourado e piscinões. 1. 2012. 236.

YAN, Z. et al. Flow conditions influence nutrient removal at an artificial lake and a drinking water reservoir with an algal floway. Algal research, v. 35, p. 245-252, 2018.

ZHANG, X. et al. Energy balance of biofuel production from biological conversion of crude glycerol. Journal of Environmental Management, v. 170, p. 169-176, 2016.

ZHAO, B., SU, Y. Process effect of microalgal-carbon dioxide fixation and biomass production: a review. Renewable and Sustainable Energy Reviews, v. 31, p. 121-132, 2014. 
